\title{
Syntheses of Organozinc Enolates and Their Reactivities in Polymerization Reactions
}

\author{
Kazunori Kataoka and Teiji Tsuruta \\ Department of Synthetic Chemistry, Faculty of Engineering, University of Tokyo, \\ 7-3, Hongo 1-chome, Bunkyo-ku, Tokyo 113, Japan.
}

(Received May 9, 1977)

\begin{abstract}
Syntheses and reactivities of organozinc enolates, having same structure as that of the chain end of growing poly(vinyl ketone) molecules, were studied. An addition reaction of $\mathrm{ZnEt}_{2}$ with ethyl styryl ketone gave an organozinc enolate, ethylzinc 5-phenyl-3-heptene-3-olate (ZE), fairly quantitatively. In the polymerization of ethyl isopropenyl ketone initiated with ethylzinc 1,3-diphenyl-1-pentene-1-olate (ZC), a secondorder rate law with respect to $\mathrm{ZC}$ was established, suggesting a coordination-addition mechanism plausible for this reaction in a way similar to the previous result with phenyl styryl ketone. At the same time as the above studies, the chemical behavior of $\mathrm{ZC}$ and $\mathrm{ZE}$ toward carbon dioxide $\left(\mathrm{CO}_{2}\right)$ was also examined. Through the measurements of time course of IR and NMR spectra of the reaction system, it was concluded that a polymeric form of organozinc enolates should be the final product formed in the reaction between $\mathrm{ZC}$ (or $\mathrm{ZE}$ ) and $\mathrm{CO}_{2}$. This polymeric organozinc compound was able to catalyze the reaction of methyloxirane with $\mathrm{CO}_{2}$ to give rise to poly(propylene carbonate) and propylene carbonate.
\end{abstract}

KEY WORDS Anionic Polymerization / Vinyl Ketone / Organozinc Enolate / Coordination-Addition Mechanism / Carbon Dioxide / Methyloxirane / Poly(propylene carbonate) / Propylene Carbonate /

In previous papers, ${ }^{1-3}$ it was reported that the successful preparation of ethylzinc 1,3-diphenyl1-pentene-1-olate (ZC),<smiles>C=[Z2]1oc(=CCCCC)c2ccccc12</smiles>

made it possible to study the mechanism of the propagation reaction of an anionic polymerization of phenyl vinyl ketone (PVK) initiated with diethylzinc $\left(\mathrm{ZnEt}_{2}\right)$, because the zinc enolate, $\mathrm{ZC}$, possessed basically the same structure as that of the chain end of the growing polymer molecules.

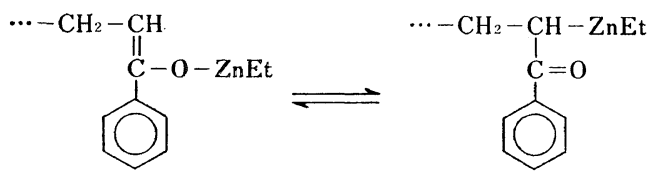

According to the kinetics as well as the spectroscopic studies, ${ }^{2,3}$ it was concluded that the mutual activation processes between the zinc enolate and PVK should be required for every propagation step. This mechanism was referred to as "coordination-addition" mechanism.

In this paper, we have tried to obtain a greater understanding of the reactivities of these organozinc enolates on several types of $\alpha, \beta$-unsaturated ketone. In order to compare the reactivity of another type of zinc enolate with that of ZC, ethylzinc 5-phenyl-3-heptene-3-olate (ZE) was prepared by reacting ethyl styryl ketone (ESK) and $\mathrm{ZnEt}_{2}$. Along with these studies, the chemical behavior of the organozinc enolates toward carbon dioxide was also examined in comparison with that of conventional organozinc alcoholates.

\section{EXPERIMENTAL}

Most of the experiments were carried out in a purified nitrogen atmosphere in order to exclude the effect of oxygen and moisture. 


\section{Reagents}

All solvents used, i.e., benzene, toluene, cyclohexane, tetrahydrofuran (THF), and dioxane, were distilled over a sodium wire under purified nitrogen. Commercial $\mathrm{ZnEt}_{2}$ was distilled under reduced pressure $\left(42^{\circ} \mathrm{C}\right.$ at $\left.46 \mathrm{mmHg}\right)$. Phenyl styryl ketone (PSK) was synthesized according to the literature $e^{4}$ and purified by recrystallization from cold petroleum ether. Ethyl styryl ketone (ESK) was prepared by the method of Asahara ${ }^{5}$ and distilled under reduced pressure $\left(88-92^{\circ} \mathrm{C}\right.$ at $1 \mathrm{mmHg}$ ).

Ethyl isopropenyl ketone (EIPK) was synthesized according to the literature ${ }^{6}$ from diethyl ketone and formalin, and distilled under reduced pressure $\left(59^{\circ} \mathrm{C}\right.$ at $\left.92 \mathrm{mmHg}\right)$. Methyloxirane was distilled twice over calcium hydride and potassium hydroxide. For the elementary reactions, gaseous carbon dioxide $\left(\mathrm{CO}_{2}\right)$ was purified by passing it through a series of columns packed with $\mathrm{CuSO}_{4}, \mathrm{KHCO}_{3}$, reduced copper, $\mathrm{P}_{2} \mathrm{O}_{5}$, and active cupric oxide before used. For the reactions carried out in an autoclave, gaseous $\mathrm{CO}_{2}$ was introduced into the autoclave directly from a cylinder.

\section{Preparation of Organozinc Enolates}

The addition product $(\mathrm{ZC})$ between PSK and $\mathrm{ZnEt}_{2}$ was prepared as described previously. ${ }^{1}$

The addition product between ESK and $\mathrm{ZnEt}_{2}$ was prepared by adding $\mathrm{ZnEt}_{2}$ with a syringe to a benzene solution $(1.0 \mathrm{~mol} / \mathrm{l})$ containing an equimolar quantity of ESK. The mixture was stirred for 72 hours at $40^{\circ} \mathrm{C}$. The formation of the addition product was proven by identification of the expected hydrolysis product, 5phenyl-3-heptanone: IR, see Figure 1; NMR, see Figure 2.

\section{Anionic Polymerization of Ethyl Isopropenyl Ketone $($ EIPK)}

A Study of the Elementary Reactions. Reactions of EIPK with organozinc enolate (ZC) were carried out in a $50-\mathrm{m} l$, one-necked flask fitted with a three-way cock, by adding a solution of ZC into a solution of EIPK. After a given time interval, the reaction was stopped with an excess of acetic acid, and the amount of phenyl 2-phenylbutyl ketone was determined by vapor-phase chromatography (VPC).

Separation of the Polymer. The polymerization of EIPK initiated with $\mathrm{ZC}$ was carried out in benzene. The reaction mixture was washed with dilute aqueous solution of hydrochloric acid, then with water and subjected to freeze-drying.

Determination of Polymer Properties. The number-average molecular weight of the polymer obtained was determined in benzene with a Mechrolab Model 301 A vapor-pressure osmometer.

Molecular weight distributions of polymer samples were measured on a Toyo Soda gelpermeation chromatograph in THF at room temperature with an elution rate of approximately $1.5 \mathrm{~m} l / \mathrm{min}$.

\section{Reaction of Organozinc Enolate and Carbon Di- oxide $\left(\mathrm{CO}_{2}\right)$}

To a solution of $10 \mathrm{mmol}$ of organozinc enolate in $20 \mathrm{ml}$ of benzene, gaseous $\mathrm{CO}_{2}$ was introduced by bubbling at room temperature under nitrogen atmosphere. After a given time interval, $0.2-\mathrm{m} l$ samples were transferred via a syringe and needle to a $0.1-\mathrm{mm} \mathrm{KBr}$-spaced cell under nitrogen atmosphere in order to measure the IR spectrum.

\section{Reaction of Methyloxirane and Carbon Dioxide} $\left(\mathrm{CO}_{2}\right)$ in the Presence of Organozinc Enolate

Procedure for the Reaction at Atmospheric Pressure. To a solution of $6 \mathrm{mmol}$ of organozinc enolate in $20 \mathrm{~m} l$ of cyclohexane, gaseous $\mathrm{CO}_{2}$ was introduced by bubbling at room temperature under nitrogen atmosphere. Then, methyloxirane $(0.8$ $\mathrm{m} l, 12 \mathrm{mmol}$ ) was injected by means of a syringe. The mixture was heated at $50^{\circ} \mathrm{C}$. After a given time interval, $0.2 \mathrm{ml}$ of the sample was transferred via syringe and needle to a $0.1-\mathrm{mm} \mathrm{KBr}$ spaced cell under nitrogen atmosphere in order to measure the IR spectrum.

When methyloxirane was used as the solvent, gaseous $\mathrm{CO}_{2}$ was introduced by bubbling at the ice-bath temperature to a solution of organozinc enolate in methyloxirane. The subsequent experimental procedure was exactly the same as that for the reaction in cyclohexane.

The amount of resulting propylene carbonate was determined by vapor-phase chromatography after quenching the reaction with acetic acid.

Procedure of the Reaction Using an Autoclave. Organozinc enolate, methyloxirane, and solvent were placed in a $200-\mathrm{m} l$ autoclave, then gaseous 
$\mathrm{CO}_{2}$ was introduced. After stirring for a definite time, the reaction mixture was diluted with benzene, and was worked up according to the following separation diagram.

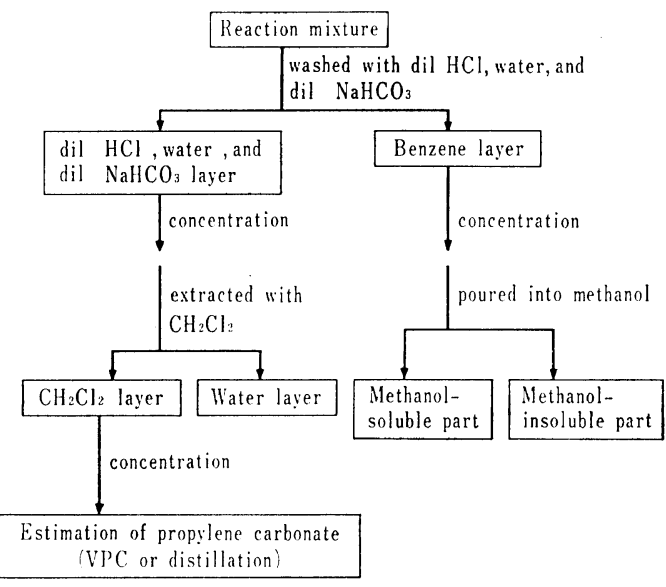

\section{RESULTS AND DISCUSSION}

Preparation of Ethylzinc 5-Phenyl-3-Heptene-3Olate $(Z E)$

$\mathrm{ZE} \mathrm{(2)} \mathrm{was} \mathrm{prepared} \mathrm{from} \mathrm{ESK} \mathrm{(1)} \mathrm{and} \mathrm{ZnEt}_{2}$ according to eq 1 .

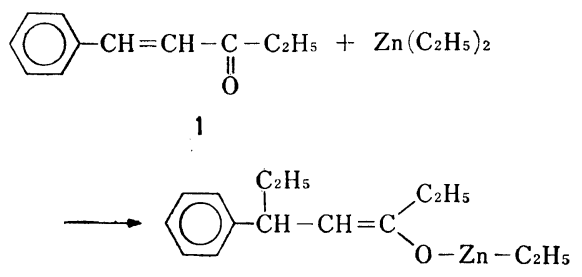

2

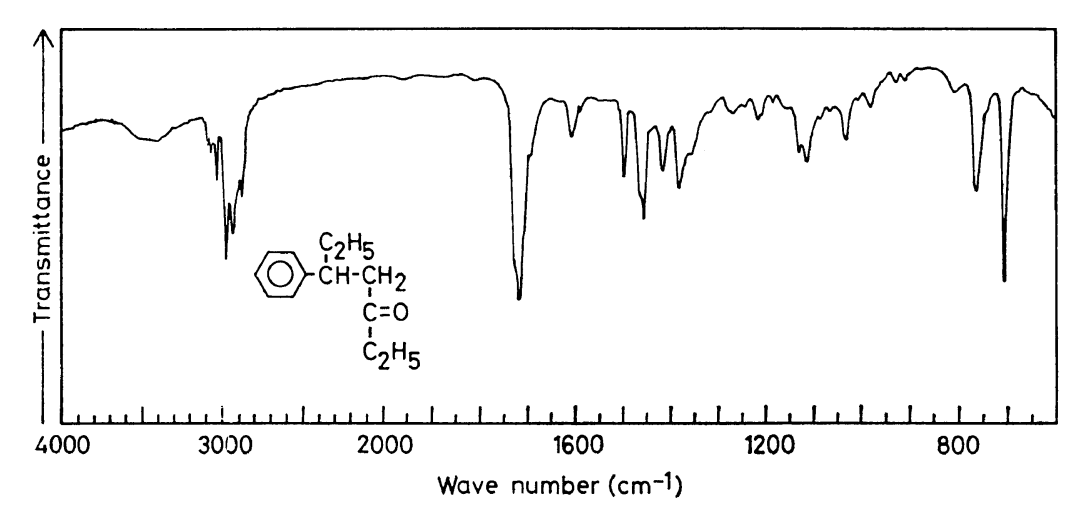

Figure 1. IR spectrum of 5-phenyl-3-heptanone (4). zation of enolate form.

The formation of $\mathbf{2}$ (or 3 ) was proven by identification of the expected hydrolysis product 4 (eq 2). IR and NMR spectra are shown in Figures 1 and 2, respectively. They are in agreement with those of the assumed structure of 5-phenyl-3-heptanone (4). From the VPC study, it was confirmed that virtually no side reaction took place, and that the conversion to $\mathrm{ZE}$ was close to $100 \%$ after a 72 -hr reaction period at $40^{\circ} \mathrm{C}$. It took relatively less a time $\left(24 \mathrm{hr}\right.$, at $\left.30^{\circ} \mathrm{C}\right)$ for the addition reaction with phenyl styryl ketone (PSK), in comparison with that for ESK (1). Moreover, ZE was less stable than ZC. The phenyl group bound to the vinyl double bond of $\mathrm{ZC}$ contributes to the stabili-

The IR spectrum of the addition product (ZE) was taken in benzene solution as shown in Figure 3a. Absorptions at 1660 and $1705 \mathrm{~cm}^{-1}$ are attributable to $\nu_{\mathrm{C}=\mathrm{C}}$ in the enolate form (2) and $\nu_{\mathrm{C}=0}$ in keto form (3), respectively. Thus, the addition product between ESK (1) and $\mathrm{ZnEt}_{2}$ is considered to be an equilibrated mixture between the enolate and keto forms, in contrast with the addition product between PSK and $\mathrm{ZnEt}_{2}$ in which the only detectable species was the 


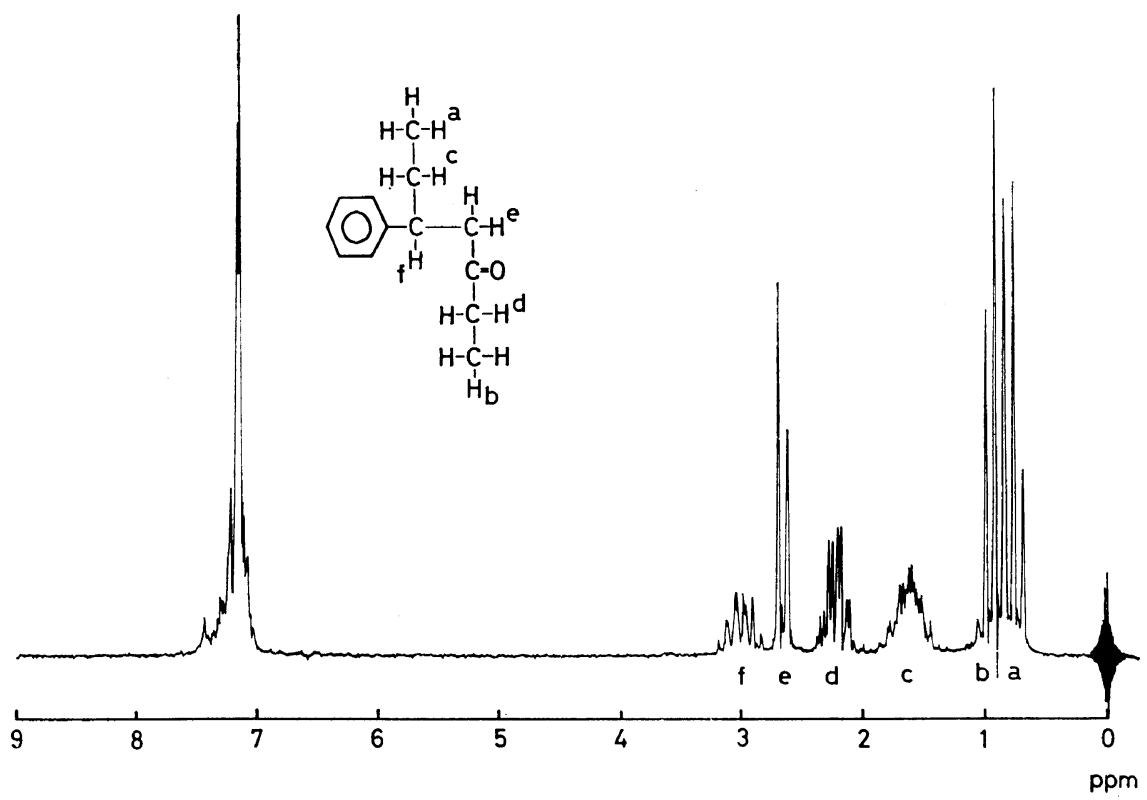

Figure 2. NMR spectrum of 5-phenyl-3-heptanone (4).

(a)

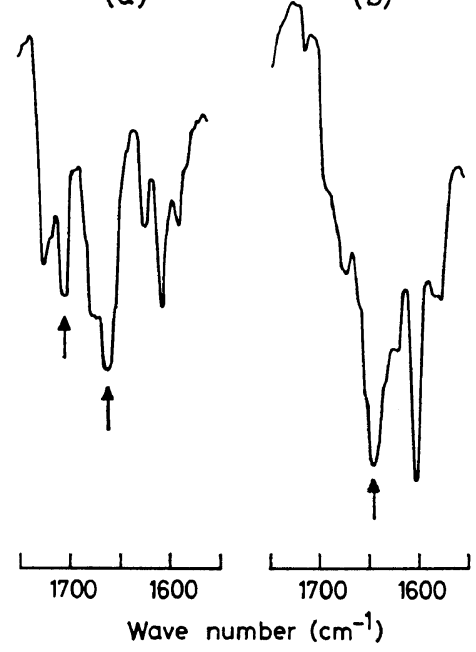

Figure 3. IR spectra of organozinc enolates in benzene solution ( $c a$. $0.5 \mathrm{~mol} / l$ ) under nitrogen atmosphere: (a) The addition product between $\mathrm{ZnEt}_{2}$ and ethyl styryl ketone (ESK). (b) The addition product between $\mathrm{ZnEt}_{2}$ and phenyl styryl ketone (PSK).

enolate form (see Figure 3b).

As the addition product between $\operatorname{ESK}(\mathbf{1})$ and $\mathrm{ZnEt}_{2}$ has the structure corresponding to that of the growing chain end of ethyl vinyl ketone in anionic polymerization induced by zinc alkyl, a certain content of the growing chain end might be present in the keto form as shown in eq 3 .

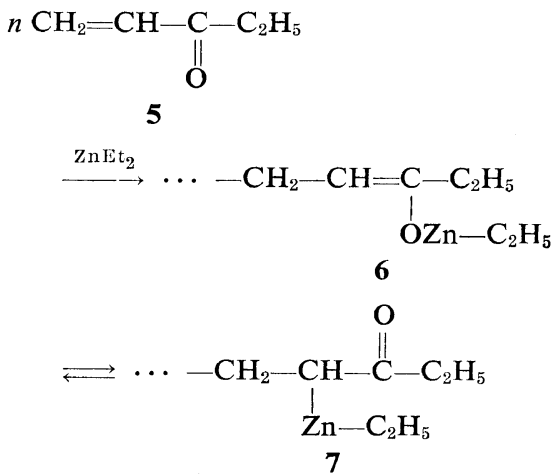

Anionic Polymerization of Ethyl Isopropenyl Ketone (EIPK) Initiated with Ethylzinc 1,3-Diphenyl-1-pentene-1-olate $(Z C)$

As reported previously, ${ }^{2}$ the anionic polymerization of phenyl vinyl ketone (PVK) exhibits the characteristic features of "living" polymerization, when $\mathrm{ZC}$ was used as initiator. It was also confirmed that no side reaction took place at least in the initial stage of the polymerization of ethyl isopropenyl ketone (EIPK). 
Syntheses and Reactivities of Organozinc Enolates

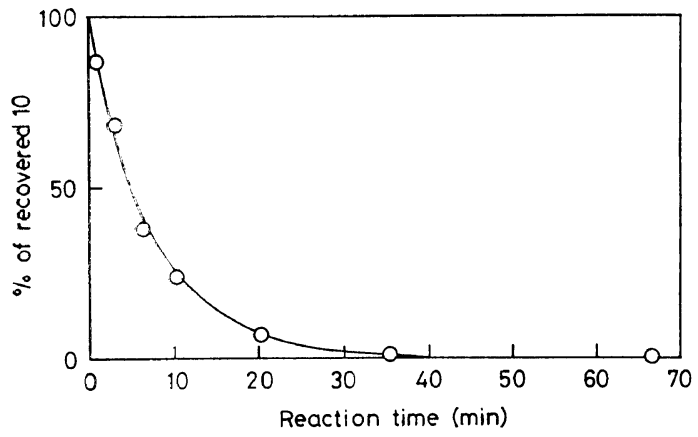

Figure 4. Reaction of ethylzinc 1,3-diphenyl-1pentene-1-olate $(\mathrm{ZC})$ with ethyl isopropenyl ketone (EIPK) in benzene: [ZC], $0.05 \mathrm{~mol} / l ;$ [EIPK], 1.0 $\mathrm{mol} / \mathrm{l}$; temp, $40^{\circ} \mathrm{C}$.

This conclusion is based on the analysis of the reaction modes between EIPK (9) and ZC (8) in benzene at $40^{\circ} \mathrm{C}$.

Figure 4 shows the results of kinetic measurement with respect to the recovered phenyl 2phenylbutyl ketone (10), which is a hydrolysis product of $\mathrm{ZC}(\mathbf{8})$, after quenching the reaction with excess acetic acid. ZC (8) was completely consumed within $40 \mathrm{~min}$, which may rule out any possibility for occurrence of a hydrogen abstruction reaction (eq 4).
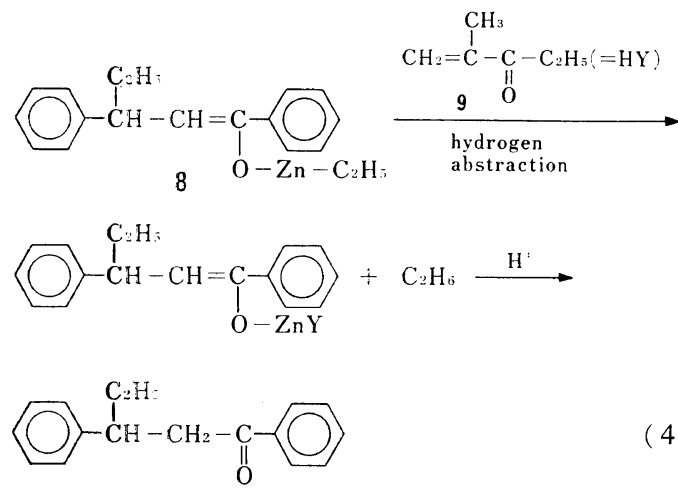

10

It was previously confirmed ${ }^{7}$ that neither carbonyl addition (eq 5) nor carbonyl reduction (eq 6) took place in the reation between dialkylzinc and $\alpha, \beta$-unsaturated ketones.

Consequently, it is quite reasonable to conclude that the only elementary reaction between ZC (8) and EIPK (9) was the conjugate addition (eq 7).

Polymer J., Vol. 9, No. 6, 1977
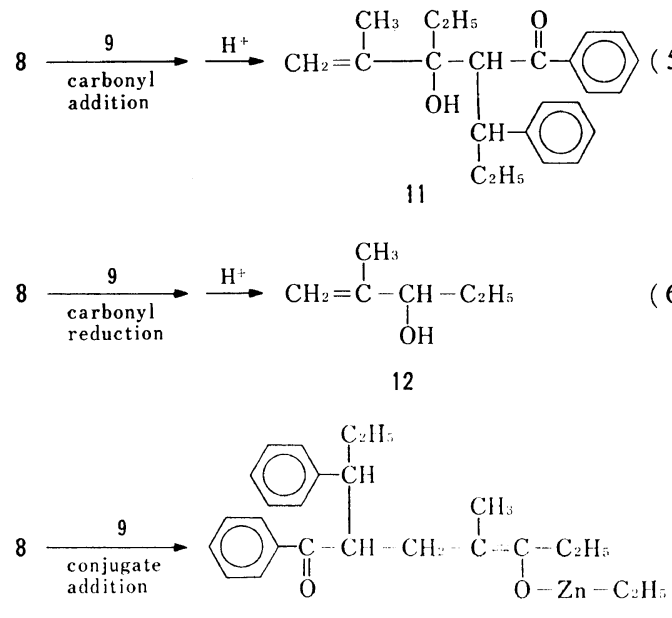

13

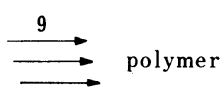

Reaction rate analyses with respect to the concentration of ZC in Figure 4 are shown in Figure 5 . Figure 5 shows that the reaction between $\mathrm{ZC}$ and EIPK is a second-order reaction with respect to $[Z C]$, which suggests that the coordination-addition mechanism is also plausible for this reaction in just the same way as it is for the reaction between $\mathrm{ZC}$ and $\mathrm{PVK}{ }^{3}$ The rate constant, however, was smaller in the reaction of ZC with EIPK than that with PVK.

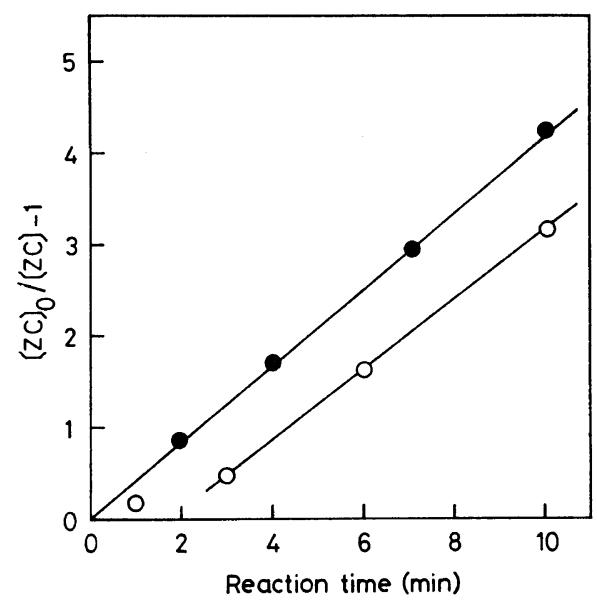

Figure 5. Kinetics of the reaction of $\mathrm{ZC}$ with EIPK and with phenyl vinyl ketone (PVK): [ZC], $0.05 \mathrm{~mol} / l ; \bigcirc$, [EIPK], $1.0 \mathrm{~mol} / l$, benzene, $40^{\circ} \mathrm{C}$; , $[\mathrm{PVK}], 1.0 \mathrm{~mol} / \mathrm{l}$, toluene, $-20^{\circ} \mathrm{C}$, taken from the work cited in ref 1 . 


\section{K. Kataoka and T. Tsuruta}

According to the coordination-addition mechanism, ${ }^{3}$ the kinetic scheme of the addition reaction of ZC (8) with EIPK (9) in benzene is derived as follows.

$$
\begin{gathered}
\mathrm{ZC}+\mathrm{EIPK} \underset{k_{2}}{\stackrel{K_{1}}{\rightleftarrows}}(\mathrm{ZC} \cdots \mathrm{EIPK}) \\
2(\mathrm{ZC} \cdots \mathrm{EIPK}) \stackrel{k_{2}}{\longrightarrow}(\mathrm{ZC} \cdots \mathrm{EIPK})+\mathbf{1 3} \\
\quad-\frac{\mathrm{d}[\mathrm{ZC}]}{\mathrm{d} t}=k_{2}\{(\mathrm{ZC} \cdots \mathrm{EIPK})\}^{2}
\end{gathered}
$$

As shown in eq 8 , the reaction proceeds via the formation of a complex. The formation of this kind of complex was confirmed previously in the reaction system of PSK with ZC based on the spectroscopic study. ${ }^{3}$ The equilibrium constant, $K_{1}$, was so large that almost all molecules of $\mathrm{ZC}$ were present in the form of a complex with PSK. If this situation is also true for the equilibrium shown in eq 8 , the rate eq 10 can be reduced to eq 11 .

$$
-\frac{\mathrm{d}[\mathrm{ZC}]}{\mathrm{d} t}=k_{2}[\mathrm{ZC}]_{\text {total }}^{2}
$$

In the initial stage of the reaction, however, the equilibrium (eq 8 ) may not yet be established.

Therefore, eq 10 cannot be reduced to eq 11 in the initial stage of the reaction. The induction period observed in Figure 5 may be explained in terms of the above considerations.

Molecular-weight distributions of polymer samples obtained in the experiments were examined by gel-permeation chromatography.

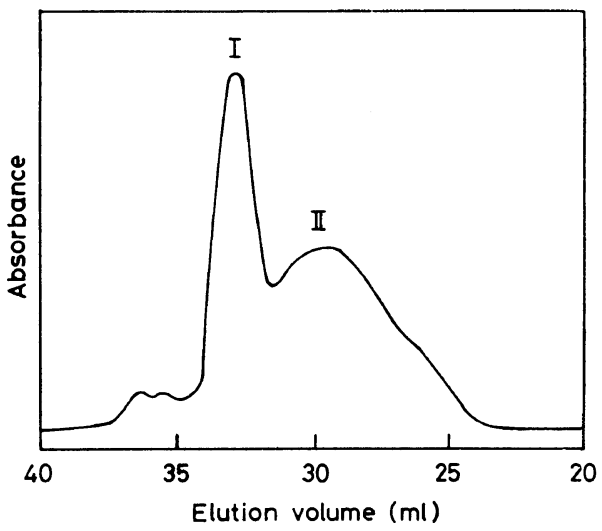

Figure 6. Gel-permeation chromatogram of poly(ethyl isopropenyl ketone): I, oligomer; II, polymer. Polymerization conditions: [ZC], $0.03 \mathrm{~mol} / l$; [EIPK], $1.5 \mathrm{~mol} / l$; solvent, benzene; $40^{\circ} \mathrm{C}$.
Every polymer exhibits bimodal molecular weight distribution in contrast with the unimodal distribution found in poly(phenyl vinyl ketone). These results are presented in part in Figure 6.

The peak molecular weight $\left(M_{n}{ }^{\mathrm{I}}\right)$ of the oligomer (fraction I) was approximately 900 . The value of $M_{n}{ }^{\mathrm{I}}$ was not influenced by conversion, reaction temperature, nor concentration of the initiator. The peak molecular weight of the hexane-insoluble part $\left(M_{n}{ }^{\mathrm{II}}\right)$, which was nearly equal to that of fraction II (Figure 6), increased with conversion as shown in Table I.

Table I. Correlation between conversion and molecular weight for hexane-insoluble poly(ethyl isopropenyl ketone) ${ }^{\mathrm{a}}$

\begin{tabular}{ccc}
$\begin{array}{c}\text { Reaction time, } \\
\mathrm{hr}\end{array}$ & $\begin{array}{c}\text { Conversion, } \\
O_{0}^{\mathrm{b}}\end{array}$ & $M_{n}{ }^{\mathrm{c}}$ \\
\hline 1 & 5.7 & 3,700 \\
2 & 11.1 & 4,200 \\
6 & 36.1 & 4,800 \\
\hline
\end{tabular}

${ }^{a}[\mathrm{EIPK}], 1.5 \mathrm{~mol} / l ;[\mathrm{ZC}], 0.03 \mathrm{~mol} / l$; benzene; temp, $40^{\circ} \mathrm{C}$.

b Based on feed (EIPK + organic residue of ZC).

c Measured by vapor-pressure osmometry.

These results indicate that a part of the growing chain end was deactivated in the early stage of the propagation to give the oligomer (fraction I), though a clear detailed mechanism has not been set forth.

A bimodal molecular-weight distribution was observed in the methyl isopropenyl ketoneorganometal system by Lyons, et al. ${ }^{8-10}$ and in the methyl methacrylate- $\alpha$-methylstyrylsodium system by Allen, et al. ${ }^{11}$

Reaction of Organozinc Enolate and Carbon Dioxide

Another unique behavior of organozinc enolate is that shown toward carbon dioxide $\left(\mathrm{CO}_{2}\right)$. In contrast with alkylzinc alcoholate, ${ }^{12}$ alkylzinc enolate was able to undergo insertion reactions with $\mathrm{CO}_{2}$.

Reactions of organozinc enolate with $\mathrm{CO}_{2}$ were examined at ambient temperatures in several solvents, e.g., benzene, dioxane, and THF. The IR spectrum of the reaction system showed absorptions at about 1600 and $1400 \mathrm{~cm}^{-1}$ in every solvent. It is widely accepted that metal carboxylate has two bands in the regions of 1610-1550 $\mathrm{cm}^{-1}$ and $1400 \mathrm{~cm}^{-1}$, which arise from the anti- 


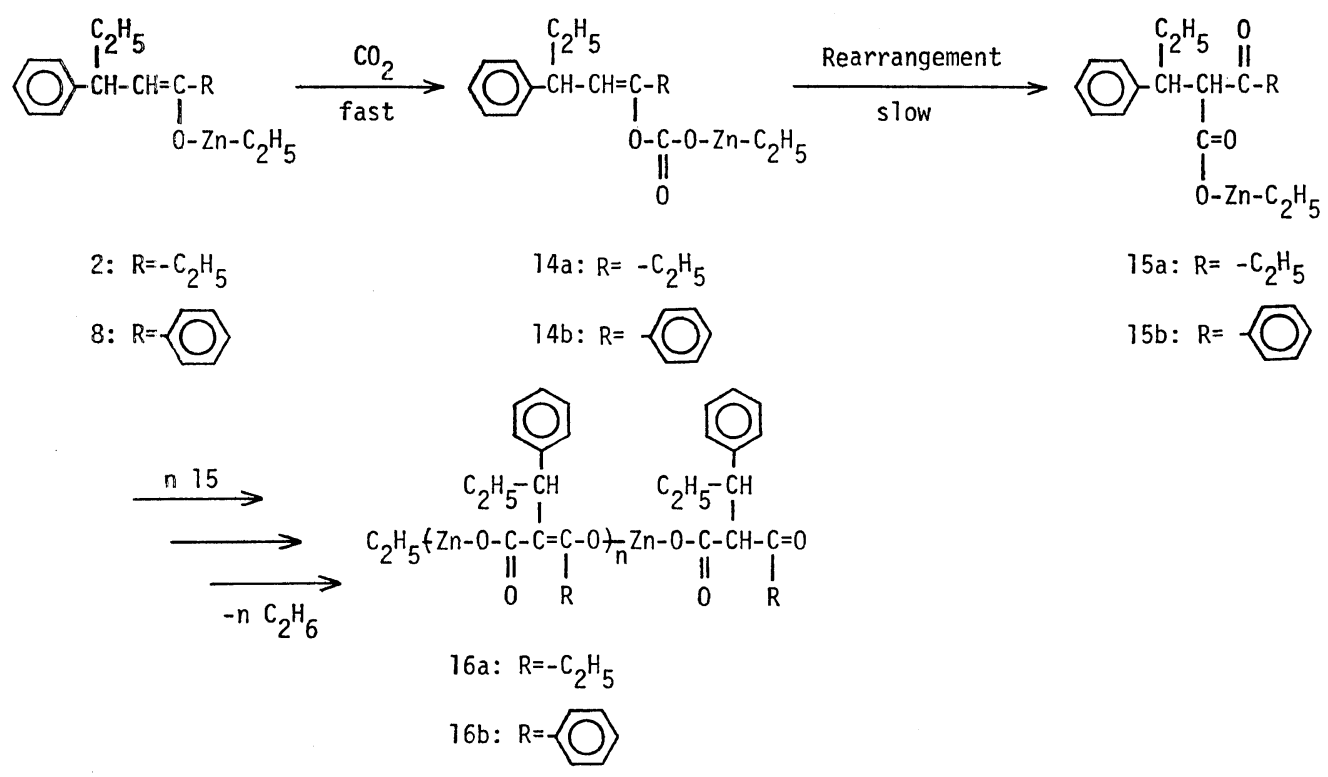

Figure 7. Mechanism of the reaction of organozinc enolate with $\mathrm{CO}_{2}$.

symmetrical and symmetrical vibrations of the $\mathrm{COO}^{-}$structure, respectively. ${ }^{13}$ Thus, two bands at 1600 and $1400 \mathrm{~cm}^{-1}$ were assigned to vibrations of the $\mathrm{COO}^{-}$structure of the reaction product. The appearance of these two bands suggests that insertion reactions of $\mathrm{CO}_{2}$ into the alkylzinc enolate took place in the reaction system.

Through the measurement of time course of IR and NMR spectra of the reaction system, it was possible to elucidate the reaction mechanism. The scheme shown in Figure 7 reasonably explains the mechanism for the reaction between the zinc enolate and $\mathrm{CO}_{2}$. This reaction mechanism was derived from the following results.

Figure 8 shows the time course of IR spectrum of $\mathrm{ZE} / \mathrm{CO}_{2}$ system. A similar time course was also observed in $\mathrm{ZC} / \mathrm{CO}_{2}$ system.

According to our previous study, ${ }^{14} \mathrm{EtZnOMe}$ has the band of stretching vibration at $519 \mathrm{~cm}^{-1}$ $\left(\nu_{\mathrm{C}-\mathrm{Zn}-\mathrm{O}}\right)$. The observed band at $570 \mathrm{~cm}^{-1}$ in Figure 8 is, therefore, assignable to the streching vibration band of structure $\mathrm{C}-\mathrm{Zn}-\mathrm{O}-\mathrm{C}=\mathrm{C}$ of $\mathrm{ZE}$. The band at $520 \mathrm{~cm}^{-1}$, whose absorbance increases in the early stage of the reaction, should be assigned to the stretching vibration band of $\mathrm{C}-\mathrm{Zn}-\mathrm{O}-\mathrm{COO}$ structure of $14 a$.

Polymer J., Vol. 9, No. 6, 1977

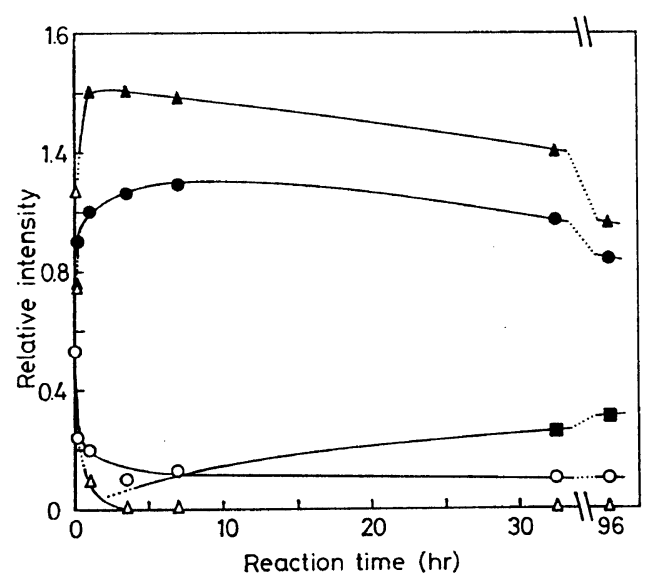

Figure 8. Time course of IR spectrum of $\mathrm{ZE} / \mathrm{CO}_{2}$ system: [ZE], $0.5 \mathrm{~mol} / l$; solvent, benzene; temp, $30^{\circ} \mathrm{C}$; 0.1-mm KBr-spaced cell; $\bigcirc, 570 \mathrm{~cm}^{-1}$,

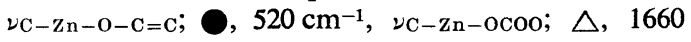
$\mathrm{cm}^{-1}, \quad \nu_{\mathrm{C}}=\mathrm{C}-\mathrm{O}-\mathrm{Zn} ; \quad \Delta, \quad 1690 \mathrm{~cm}^{-1}, \quad \nu_{\mathrm{C}}=\mathrm{c}-0 \mathrm{OCOOZn}$;

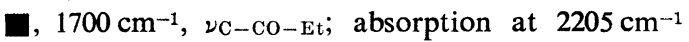
(assigned to benzene) as internal standard of relative intensity.

In the $\mathrm{ZE} / \mathrm{CO}_{2}$ system, absorptions arising from $\nu_{\mathrm{C}=\mathrm{C}-\mathrm{Ozn}}$ and $\nu_{\mathrm{C}=\mathrm{C}-\mathrm{Ocoozn}}$ are clearly separated from each other, viz., $\nu_{\mathrm{C}=\mathrm{C}-\mathrm{Ozn}}$ at 1660 $\mathrm{cm}^{-1}$ and $\nu_{\mathrm{C}=\mathrm{C}-\mathrm{OCOOZn}}$ at $1690 \mathrm{~cm}^{-1}$. The corresponding two absorptions in $\mathrm{ZC} / \mathrm{CO}_{2}$ system 
seemed to appear in the same region (ca. 1645 $\mathrm{cm}^{-1}$ ).

As the insertion of $\mathrm{CO}_{2}$ into the $\mathrm{O}-\mathrm{Zn}$ bond of $\mathrm{ZE}$ took place, the rapid appearance of the absorption at $1690 \mathrm{~cm}^{-1}\left(\nu_{\mathrm{C}=\mathrm{C}-\mathrm{OCOOZn}}\right)$, at the expense of the absorption at $1660 \mathrm{~cm}^{-1}\left(v_{\mathrm{C}=\mathrm{C}-\mathrm{OZn}}\right)$, was observed.

The second stage of the reaction is characterized by a rearrangement reaction of 14 . The absorptions at $1690 \mathrm{~cm}^{-1}\left(\nu_{\mathrm{C}=\mathrm{C}-\mathrm{OCOOZn}}\right)$ and at $520 \mathrm{~cm}^{-1}\left(\nu_{\mathrm{C}-\mathrm{Zn}-\mathrm{OCOO}}\right)$ slowly decrease, whereas the absorption at $1700 \mathrm{~cm}^{-1}$, arising from the vibration of $\mathrm{C}-\mathrm{CO}-\mathrm{Et}$ structure of $15 \mathrm{a}$, gradually increases.

The third stage of the reaction are the condensation reactions of 15 . The intermolecular condensation took place between the $\mathrm{ZnEt}$ residue and the active methine of $\mathbf{1 5}$ with the elimination of ethane. Figure 9 shows the NMR spectra of the reaction system $\left(\mathrm{ZC} / \mathrm{CO}_{2}\right.$ system). The reaction with $\mathrm{CO}_{2}$ resulted in the broadening of the whole spectrum. The methine proton $(\delta 5.7 \mathrm{ppm})$ and $\mathrm{Zn}-\mathrm{C}_{2} \mathrm{H}_{5}$ proton $(\delta 0.2$ and 0.9 ppm) disappeared after the reaction, whereas a singlet peak arising from eliminated ethane $(\delta 0.9$ ppm) a ppeared.

The fact that gelation of the reaction system occurred after a long time period also suggests the formation of polymeric zinc compound 16 .

The IR spectrum of the reaction system, after

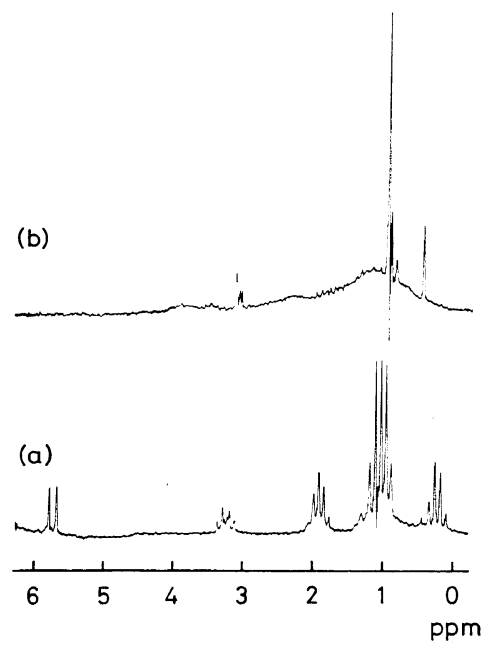

Figure 9. NMR spectra of $\mathrm{ZC} / \mathrm{CO}_{2}$ system: [ZC], $0.5 \mathrm{~mol} / l$; a, before bubbling $\mathrm{CO}_{2} ; \mathrm{b}$, after bubbling $\mathrm{CO}_{2}$ (reaction time, 2 days). a long time period, shows large and broad bands at the region of $1550-1600 \mathrm{~cm}^{-1}$, arising presumably from structure $(\mathrm{Zn}-\mathrm{OCO}-\mathrm{C}=\mathrm{C}-\mathrm{O}-)_{\bar{n}}$ of 16.

When the hydrolysis of the reaction system was carried out by the use of dilute hydrochloric acid, 5-phenyl-3-heptanone (4) or phenyl 2-phenylbutyl ketone (10) was obtained in quantitative yield. No keto acid was obtained at all. The reaction products $(14,15$, and 16$)$ seem to undergo a decarboxylation reaction quite easily. Reaction of Carbon Dioxide $\left(\mathrm{CO}_{2}\right)$ and Methyloxirane Using Organozinc Enolate $\mathrm{CO}_{2}$ System as Catalyst

The reaction products between zinc enolate and $\mathrm{CO}_{2}\left(\mathrm{ZC} / \mathrm{CO}_{2}\right.$ or $\mathrm{ZE} / \mathrm{CO}_{2}$ system) was found to catalyze the reaction between methyloxirane

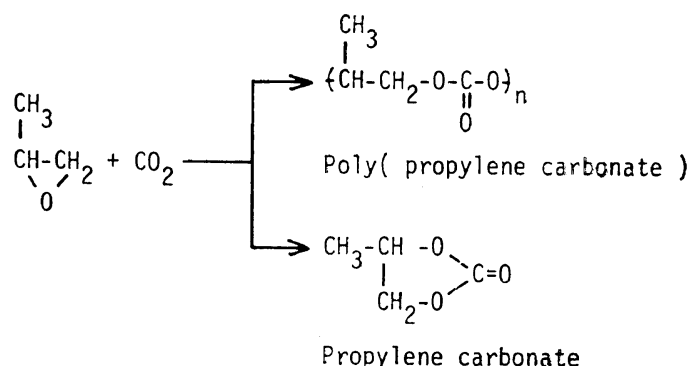

Figure 10. Reaction modes of $\mathrm{CO}_{2}$ with methyloxirane. (a)

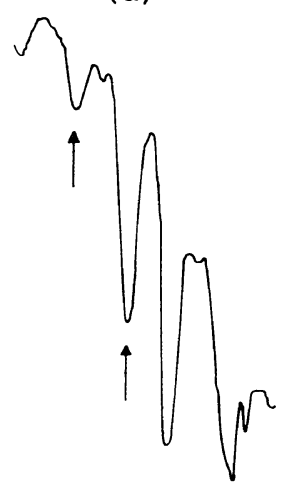

$19001800 \quad 17001600$ (b)

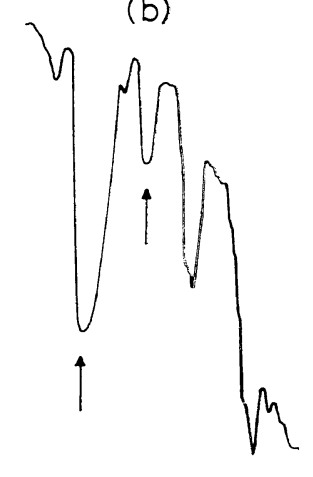

Figure 11. IR spectra of $\mathrm{ZC} / \mathrm{CO}_{2} /$ methyloxirane systems: a, solvent, methyloxirane, room temp, 5 days; $b$, solvent, cyclohexane, $50^{\circ} \mathrm{C}, 17$ days. 
Syntheses and Reactivities of Organozinc Enolates

Table II. Reaction of methyloxirane and $\mathrm{CO}_{2}$ in the presence of $\mathrm{ZC}^{a}$

\begin{tabular}{|c|c|c|c|c|c|c|}
\hline \multirow{3}{*}{ Run } & \multirow{3}{*}{$\underset{{ }^{\circ} \mathbf{C}}{\text { Temp }}$} & \multirow{3}{*}{$\begin{array}{l}\text { Press, } \\
\text { atm }\end{array}$} & \multirow{3}{*}{$\begin{array}{c}\text { Aging, } \\
\text { day }\end{array}$} & \multirow{3}{*}{$\begin{array}{l}\text { Propylene } \\
\text { carbonate, } \\
\text { g(yield \%) }\end{array}$} & \multicolumn{2}{|l|}{ Products } \\
\hline & & & & & Poly(propylene & carbonate) \\
\hline & & & & & $\begin{array}{c}\text { MeOH-insoluble, } \\
\text { g }\end{array}$ & $\begin{array}{c}\mathrm{MeOH} \text {-soluble, } \\
\mathrm{g}\end{array}$ \\
\hline 1 & 60 & 50 & - & $3.5(10)$ & 0.062 & 4.3 \\
\hline 2 & 35 & 60 & - & $0.34(1.0)$ & 0.017 & 6.4 \\
\hline 3 & 60 & 60 & 8 & $1.62(4.0)$ & 0.160 & 4.9 \\
\hline 4 & 35 & 40 & 8 & $0.62(1.6)$ & 0.177 & 4.7 \\
\hline
\end{tabular}

a Solvent, benzene $(50 \mathrm{ml})$; reaction time, 7 days; methyloxirane, $0.4 \mathrm{~mol} ; \mathrm{ZC}, 0.02 \mathrm{~mol}$.

and $\mathrm{CO}_{2}$. As shown in Figure 10, the main products are poly(propylene carbonate) and propylene carbonate.

Figures 11a and $b$ show the IR spectra of the reaction system. The absorptions at $1750 \mathrm{~cm}^{-1}$ and $1820 \mathrm{~cm}^{-1}$ were assigned to the stretching vibration $\left(\nu_{\mathrm{C}=0}\right)$ of poly(propylene carbonate) and propylene carbonate, respectively. These assignments were confirmed by measuring the spectra of the authentic samples. It was also observed that the absorption arising from $\nu_{\mathrm{C}=\mathrm{O}}$ of propylene carbonate shifts slightly in different solvents in the range of about $1800 \mathrm{~cm}^{-1}$ to $1840 \mathrm{~cm}^{-1}$.

As can be seen from Figures 11a and b, propylene carbonate was the main product at $50^{\circ} \mathrm{C}, 1 \mathrm{~atm}$. At room temperature, however, poly(propylene carbonate) was the main product. The quantity of propylene carbonate formed was determined on the basis of VPC. Only $2.3 \mathrm{mmol}$ of propylene carbonate $(40 \%$ to feed zinc) was formed in 2 weeks at $50^{\circ} \mathrm{C}, 1 \mathrm{~atm}$.

Table II lists the experimental results which were obtained by using an autoclave. The methanol-insoluble part was identified as poly(propylene carbonate) on the basis of IR and NMR spectroscopy. The methanol-soluble part seems to consist of a mixture of the hydrolysis product of catalyst (4 or 10) and low-molecular-weight poly(propylene carbonate). Propylene carbonate was indentified by IR and NMR spectroscopy.

Aging of the catalyst system was carried out in runs 3 and 4 . The activity of the catalyst system in terms of production of the methanolinsoluble poly(propylene carbonate) was increased by a procedure of aging catalyst. As the $n$ value in compound $(-\mathrm{C}=\mathrm{C}-\mathrm{O}-\mathrm{Zn}-\mathrm{OCO})_{-}(\mathbf{1 6})$ is considered to increase with the aging period, the highly polycondensed zinc species (16) may be favorable for the formation of high-molecular-weight poly(propylene carbonate). A similar phenomenon was previously observed in $\mathrm{ZnEt}_{2} /$ dihydric phenol system, ${ }^{15}$ where the activity of the catalyst systems has close relation with the $n$ value in compound 17 .

$$
\left.\mathrm{C}_{2} \mathrm{H}_{5}+\mathrm{Zn}-\mathrm{O}-\bigcirc{ }^{\mathrm{O}}\right)^{\mathrm{H}}
$$

17

Acknowledgment. We are very grateful to Dr. R. Tsushima for his helpful advise in earlier stages of this study.

\section{REFERENCES}

1. R. Tsushima and T. Tsuruta, Makroml. Chem., 166, 325 (1973).

2. R. Tsushima and T. Tsuruta, J. Polym. Sci., Part A-1, 12, 183 (1974).

3. T. Tsuruta and R. Tsushima, Makromol. Chem., 177, 337 (1976).

4. H. Gilman, "Organic Syntheses," Vol. I, Wiley, New York, N.Y., 1956, p 78.

5. T. Sato, H. Kise, M. Seno, and T. Asahara, Nippon Kagaku Kaishi (J. Chem. Soc. Japan), 1245 (1974).

6. J. Colonge and L. Cumet, Bull. Soc. Chim. Fr., 838 (1947).

7. Y. Kawakami, Y. Yasuda, and T. Tsuruta, $J$. Macromol. Sci.-Chem., A3, 205 (1969).

8. A. R. Lyons and E. Catterall, Eur. Polym. J., 7, 839 (1971).

9. A. R. Lyons and E. Catterall, Eur. Polym. J., 7, 849 (1971).

10. A. R. Lyons and E. Catterall, J. Polym. Sci., 
Pait A-1, 9, 1335 (1971).

11. P. E. M. Allen, R. P. Chaplin, and D. O. Jordan, Eur. Polym. J., 8, 271 (1972).

12. S. Inoue, M. Kobayashi, H. Koinuma, and T. Tsuruta, Makromol. Chem., 155, 61 (1972).

13. L. J. Bellamy, "The Infrared Spectra of Com- plex Molecules," Methuen, London, 1958, p 174.

14. M. Ishimori and T. Tsuruta, Makromol. Chem., 64, 190 (1963).

15. M. Kobayashi, Y. L. Tang, T. Tsuruta, and S. Inoue, Makromol. Chem., 169, 69 (1973). 